\title{
O Present Perfect para Brasileiros: \\ Tradução Transcultural no Ensino-Aprendizagem de Língua Inglesa
}

\author{
Heleno Álvares Bezerra Júnior \\ Universidade Severino Sombra, Curso de Letras e Programa \\ do Mestrado em História, Universidade Castelo Branco e \\ Universidade do Estado do Rio de Janeiro \\ helenobj@yahoo.com.br
}

\begin{abstract}
Resumo: Com base na prática reflexiva e estudos sobre tradução transcultural, o artigo pretende atingir dois públicos-alvo: pesquisadores comprometidos com o desenvolvimento de novas abordagens para o ensino de língua inglesa e alunos que apresentem dificuldades de compreensão do Present Perfect de acordo com a língua padrão. Preocupados com ambos os grupos, esperamos, por um lado, discutir questões transculturais importantes à tradução deste tempo verbal para a língua portuguesa e, por outro lado, apontar dicas práticas para estudantes el ou meros usuários da língua inglesa no tocante à temática.
\end{abstract}

Palavras-chave: Prática Reflexiva. Transculturalismo. Tradução. EnsinoAprendizagem Sociocultural.

\section{The Present Perfect for Brazilians: Transcultural Translation in Languange Teaching And Learning}

\begin{abstract}
Based on studies concerning reflexive practice and transcultural translation, this paper aims at addressing two target groups: scholars commited with the development of new approaches to English language teaching as well as undergraduates (or other language students) in need of understanding the many uses of the Present Perfect according to standard language. Concerned with this bifold reading public, I intend to present, on the one hand, important transcultural questions regarding the translation of such English tense into Portuguese and, on the other hand, to point out practical hints to students and/ or ordinary users of the language about this subject matter.
\end{abstract}

Keywords: Reflexive Practive. Transculturalism. Translation. Sociocultural Approach to Language Learning and Teaching. 


\section{Ao Público Acadêmico: Motivações da Prática Reflexiva}

O presente artigo é, em parte, fruto de uma inquietação pessoal, enquanto professor de língua inglesa há quinze anos e, por outro lado, consequência de resultados positivos, colhidos durante a prática de ensino com três grupos distintos: 1) alunos de cursos de inglês entre o fim do nível básico e início do intermediário (a partir de quinze anos de idade) por meio da tradução; 2) alunos universitários que receberam o Present Perfect ao longo de aulas ministradas em inglês; 3 ) grupos também do terceiro grau que precisaram não só de explicações em língua materna, mas também de transposições de tal estrutura verbal para o português.

Conscientes de que o posicionamento autocrítico do professor deve ser uma constante para que a relação ensino-aprendizam se estabeleça de modo viável e eficaz, inspiramo-nos no pedagogo Tony Ghaye (2011), segundo o qual, o sujeito constrói sua identidade, enquanto educador, a partir de suas práticas e construções de valores: "One of the fundamental purposes of learning through reflection is to improve the quality of teaching and learning. Understanding the role of personal and professional values in this process is important. Values give educators a sense of professional identity. They also motivate and provide them with reasons for teaching"1 (GHAYE, 2011, p. 10).

Motivados por tal pensamento e por teorias culturalistas da tradução associadas a comparativismos gramaticais, organizamos esse relato de experiência, na esperança de que o mesmo possa auxiliar outros tantos brasileiros que considerem o Present Perfect algo inacessível. Apesar das limitações que qualquer material didático ou teórico possa conter, esperamos que a abordagem aqui apresentada venha elucidar aspectos culturais, semânticos e situacionais da estrutura em voga, de modo a desmitificar a apreensividade gerada em torno do Present Perfect.

Os seguintes depoimentos aqui selecionados compõem umfeedback inicial do experimento, ainda em um processo de construção autocrítico. Esclarecemos, de antemão, que tais relatos não representam dados vangloriosos, mas que consistem em uma resposta inicial, que nos estimulam a divulgar saldos positivos no decorrer do exercício educacional. Mesmo tendo entrevistado alunos de instituições distintas, não acrescentaremos todas por concisão, assinalando somente aquelas que mais nos encorajaram a levar a pesquisa adiante.

As primeiras experiências em sala de aula surgiram em um curso de inglês, onde, utilizando uma linguagem bem simples, tivemos a ousadia de romper com o protocolo da língua estrangeira e ministrar, excepcionalmente, uma aula expositiva em língua materna. A adoção do português justificou-se pela expectativa de que os alunos captassem as diferentes nuances do Present Perfect de forma imediata. A explanação foi seguida de exercícios comunicativos e ilustrações contextuais que aplicassem o Present Perfect a situações do quotidiano. Tal aula foi seguida de outras nas quais voltamos a abordar o tempo verbal em inglês, seguindo o conteúdo programático dos métodos Blueprint 1 (ABBS \& FREEMAN, 1990) e American headway 2 (SOARS \& SOARS, 2001). Nossa consideração reflexiva obteve respostas como a de Thiago, 15 anos, aluno do Intermediário I, o qual afirmou espontaneamente: "Pô, eu achei bem maneira essa forma de falar do Present Perfect. Cara! Isso não entrava na minha cabeça, e essa 'paradinha' tirou um 
monte de 'grilo'. Podes crer. Ficou bem mais fácil. Pra mim, pelo menos, valeu, teacher" (1999).

Anos mais tarde, ministrando uma disciplina sobre 'Aspectos Semântico-Pragmáticos do Verbo em Língua Inglesa em uma universidade, trabalhamos com "The tense-aspect system: forms and meanings" (CELCI \& LARSE, 1993) como discussão inicial, a fim de provar que o estudo sobre time após o conhecimento dos tenses seria muito mais proveitosó para o sujeito em aquisição da língua estrangeira. Durante aquele semestre, as referências básicas para a prática em sala de aula vieram de $A$ university grammar of English (GREENBAUM \& QUIRK, 1973), A University course in English (DOWNING \& LOCK, 1992). Use of grammar: meaning and form (McLEOD \& WOODS, 1990), English grammar (COBUILD, 2004), Longman English Grammar (ALEXANDER, 1988), The Heinemann English grammar (BEAUMONT, 1992) e Meaning and the English verb (LEECH, 2004).

Em tal curso, o enfoque foi bem mais aprofundado, com aulas lecionadas em língua inglesa. Entretanto, procuramos perceber como e até que ponto os alunos assimilavam o posicionamento de autores estrangeiros, estudados em abordagem comparativa. E, em dado momento, atentamo-nos para a necessidade de assinalar alguns choques de percepção de mundo entre o brasileiro e o nativo de língua inglesa, ou seja, uma distância entre a mentalidade dos gramáticos que escrevem para estudantes do mundo todo e a receptividade de falantes de português a estes materiais.

A partir deste insight, obtivemos um retorno positivo, como a seguinte declaração da aluna Luciana: "I'd never seen a way to put the Present Perfect this plain. Really straight. I loved it" (2005). Débora, da mesma instituição universitária, relatou: "Heleno, I don't mean to flatter you, but I will always think of Present Perfect as 'before you' and 'after you'. Ha, ha, ha" (2005). Em outra instituição universitária, encontramos turmas mais heterogêneas, que precisavam de um aparato didático mais detalhado. Neste caso, agrupamos tenses, trabalhando-os um após outro dentro de um estudo sobre time. Deste modo, um determinado tense, por exemplo, chegou a ser apresentado mais de uma vez, conforme a situação e a referência temporal específica de cada ocasião. Em tais turmas, confeccionamos materiais que, mesmo preservando as visões dos autores citados, partissem do contexto para a teoria. Para referências de consulta e exercícios, adotamos o How English Works (SWAN \& WALTER, 1997), Intermediate Grammar: from Form to Meaning and Use (BLAND, 1996), Grammar Spectrum 3 (COE, 1995), Grammar Practice in Context (BOLTON \& GOODEY, 1997), e English Grammar in Use (MURPHY, 1985). A fim de reconhecer os múltiplos sentidos de um tense, alunos foram divididos em grupos, responsáveis por analisar as ocorrências do Present Perfect em capítulos distintos da adaptação de Hamlet por Chris Rice (2000) para alunos préintermediários da editora Penguin. Tendo cada equipe trabalhado com atos diferentes da peça, a aluna Luciana disse: "Aprendi o Present Perfect com você. Também, depois da lavagem cerebral, não deu para ser diferente" (2008).

O Present Perfect apresenta, às vezes, certa incompatibilidade com a língua portuguesa, gerando tensões transculturais que, em alguma medida, nos remetem a disparidades importantes em estudos sobre tradução. Embora hoje muito se fale sobre a intraduzibilidade 
de expressões idiomáticas específicas sem correspondência literal, existem também casos de traduzibilidade parcial e traduzibilidade inconstante entre tempos verbais de duas línguas distintas. O segundo caso particularmente pode, assim, gerar o fenômeno da traduzibilidade múltipla, ou, 'equivalência na diferença' (JAKOBSON, 2000). Como afirma o mesmo linguista, "on the level of interlingual translation, there is ordinarily no full equivalence between code-units" .

Diríamos, então, que, mais que um descompasso estrutural ocasional entre dois idiomas, as idiossincrasias que produzem esta multiplicidade de compreensões estão ligadas a implicações maiores que transpõem aspectos sintáticos, atingem a esfera do contexto, da pragmática, da cultura chegando a níveis mais profundos como a análise do discurso. Entretanto, usando a morfossintaxe como ponto de partida para outras reflexões, Heloísa Gonçalves Barbosa (2004) expõe o seguinte:

[Um] [...] aspecto que serve de base para esta proposta de categorização são as dificuldades que se encontram no ato de transpor uma língua para outra, tal como apresentadas por Mounin (1963): 1) as diferenças das realidades extralinguísticas que cercam os povos falantes das várias línguas; 2) as diversas maneiras como cada sistema linguístico divide e analisa as experiências da realidade extralinguística; 3) as organizações diversas dos sistemas linguísticos, seja ao nível morfológico ou sintático; e 4) as divergências estilísticas, que se podem considerar aqui como diferenças de registro, da probabilidade de ocorrência de um enunciado e o do grau de adequação de um enunciado a uma situação (BARBOSA, 2004, p. 91).

Segundo David Crystal (1976), os estudos sobre tradução nos dão hoje uma dimensão mais profunda sobre a complexidade e imperfeição do signo linguístico. Transcendendo as fronteiras da hermenêutica e da semiótica, estes novos estudos abraçam uma abordagem interdisciplinar que, mesmo admitindo as inestimáveis contribuições linguísticas de John Rupert Firth (1937), John Cunnison Catford (1965) e Eugene A. Nida (1969), rumam a uma compreensão mais ampla sobre o fenômeno da tradução (CRYSTAL, 1976, p. 323). Em conformidade com Crystal, Paul Ricœur (2011) vislumbra os avanços de tais estudos sobre a tradução, ressaltando a conscientização do homem contemporâneo acerca de suas limitações linguístico-culturais e a desilusão com um mundo perfeitamente traduzível:

A felicidade momentânea, historicamente circunscrita, de traduzir, implica a aceitação de uma perda: o abandono do sonho de tradução perfeita, de um absoluto linguístico que aboliria a diferença entre o próprio e o estrangeiro. Deixando de lado esta aspiração irrealizável, o tradutor encontra sua recompensa, seu ganho, no próprio reconhecimento do estatuto incontornável da dialogicidade do ato de traduzir como horizonte razoável do desejo de traduzir (RICEUR, 2011, p. 8).

No tocante às fronteiras culturais entre o Present Perfect e a língua portuguesa, é válido ressaltar que não nos deparamos com o fenômeno da intraduzibilidade stricto sensu; mas com uma estrutura polissêmica cuja compreensão precisa se dar contextualmente. 
Por isso, atrelamos a relação Present Perfect / língua portuguesa ao que dizem Pontes e Batalha (2004):

[...] apesar dos limites da traduzibilidade - e para além desses limites a tradução favorece uma maior aproximação entre os povos e que, por conseguinte, toda vez que lidamos com a cultura do outro, somos levados a refletir sobre mós mesmos com relação a esse outro com quem dialogamos. Se a tradução favorece o acesso a outras leituras de mundo, enriquecendo a rede de intertextualidade, de interdisciplinaridade e de interculturalidade entre os povos, ela também suscita a reflexão sobre o estatuto do texto traduzido. Por outro lado, a responsabilidade de tecer uma rede de conivência entre culturas implica uma postura político-filosófica [...] (PONTES JR \& BATALHA, 2004, p. 9).

Ora, se o estudo sobre a tradução do Present Perfect envolve questões político-filosóficas, vejamos o que nos diz Edwin Gentzler (2009), sobre a transculturalidade. Fazendo alusão ao famoso conceito de différance de Jacques Derrida, Edwin Gentzler (2009) sugere que traduzir signifique reconhecer diferenças. Tal pensamento se aplica à presente discussão porque, embora a estrutura do Present Perfect exista literalmente na sintaxe portuguesa, verter as ideias do mesmo tempo verbal para nosso idioma implica na adoção de diferenças não só sintáticas, mas culturais que, de certa forma, marcam a différance sobre a qual fala Derrida (GENTZLER, 2009, p. 197).

Quanto aos impasses da tradução, Theo Hermans (1998) também afirma ironicamente que, se a palavra possui natureza divina, existem problemas quanto à sua natureza ainda insolúveis: "[s]e é verdade que no princípio foi o verbo, então, quase a partir do princípio houve um problema de tradução. Ou melhor, há neste princípio um problema de tradução que ainda está aqui, neste princípio, nessa palavra que se encontrava aqui quando comecei" (p. 7). Embora, para Hermans, 'verbo' signifique 'palavra', nada nos impede restringilo ao sentido gramatical. Afinal, aquilo que designa ações ou estado também constitui uma palavra. Por todos estes motivos, a tradução do Present Perfect exige discernimento e adaptação sintática. Assim, o tradutor de tal tempo verbal deve posicionar-se como "aquele que prevê o acesso [ao significado], removendo barreiras, guiando através de lacunas que impedem a compreensão" (HERMANS, 1998, p. 10) ou alguém que evita traduções artificiais.

Se entendermos que cada língua é fruto de culturas que se diferem entre si, é possível conceber que "a vivência da alteridade se produz entre os diversos povos" (PONTES JR. \& BATALHA, 2004, p. 29). Intensificando essa abordagem, é possível percebermos que as diferenças linguísticas aqui representadas nada mais são que reflexos das peculiaridades culturais dos povos, suas tradições, hábitos, valores, visão de mundo e tudo mais. Conforme afirma José Lambert (2011),

[...] todas as tradições linguísticas coincidem com o princípio das nações, além de que, no mundo inteiro, outros tipos de fronteiras são exceções, na pior das hipóteses). A tradução é um bom exemplo para discussão desses princípios porque, por definição, as traduções atuam tanto no interior de nações específicas 
como fora delas, mas também no interior de línguas específicas, embora importem pelo menos alguns aspectos de outra língua ou diversas línguas. Esse fato reafirma mais uma vez que as línguas não podem ter as mesmas fronteiras que as unidades políticas, visto que toda tradução constitui-se, pelo menos em parte, de uma mistura de línguas (p. 47).

Enfim, todas estas reflexões fazem-nos concluir que, para estudarmos (e principalmente ensinarmos) um tempo verbal como Present Perfect, precisamos pensar em todas as implicações que o mesmo apresente, de modo a propor soluções plausíveis, não só para que a tradução de tal estrutura se dê efetivamente para o português sem artificialidade, mas também para que o brasileiro se sinta seguro para empregar tal tempo verbal quer na escrita quer na prática oral. Então, aqui vão sugestões que permitem o falante de língua portuguesa entender a linha de raciocínio do gramático anglófono, as dificuldades dos próprios nativos quanto à compreensão da gramática e como o sujeito lusófono pode interagir com o Present Perfect sem traumas.

Como já esclarecemos, o material aqui apresentado é uma segunda versão do texto original que, apesar de mais simples, visava a alcançar adolescentes e estudantes que utilizavam o inglês para comunicação quotidiana. A presente abordagem, contendo termos técnicos e teóricos, também é dedicada a futuros professores de língua inglesa que estejam cursando, preferencialmente, programas como Português/Inglês ou Inglês/Literaturas de Língua Inglesa, o que não impede que um outro público leitor entre em contato com o assunto em discussão. Os resultados obtidos em princípio não têm como objetivo apontar o presente texto como método infalível ou resposta definitiva a nossas constantes indagações como educadores. O que pretendemos é levantar, a partir de retornos iniciais, uma pesquisa quantiqualitativa, observando até que ponto a leitura deste texto, agora voltado para professores de língua estrangeira em formação, sana, ou, ao menos, minimiza dúvidas acerca do Present Perfect. Resultado este que também elucidará o grau de (in)eficácia do artigo junto ao(s) público(s)-alvo de maior abrangência, apontando a necessidade de implementações posteriores. E, neste sentido, visamos a avaliar, em outro momento, a qualidade, a clareza e o grau de dificuldade de leitura deste material. Para aqueles que nos lêem neste instante, desejamos que o texto sirva de auxílio para uma melhor interatividade com uma estrutura tão recorrente e agradável em língua inglesa.

\section{A usuários da língua inglesa}

\section{O brasileiro e o Present Perfect: implicações transculturais entre o português e inglês}

$\mathrm{Na}$ escola, o aluno ouve falar de 'presente', 'passado' e 'futuro' em língua portuguesa, como se estas ideias aplicadas à vida prática, fora do universo linguístico, fossem iguais às noções de 'presente', 'passado' e 'futuro', contidas em tempos verbais. Espera-se que o 'presente que conjugamos' seja igual ao 'presente do relógio'. Mas, por exemplo, será que isto é verdade? Será que o Present Perfect se refere ao 'agora' porque possui dentro de si a palavra present? E, se contém o nome present, por que não se reporta ao presente somente? Antes de respondermos a estas perguntas, gostaríamos de esclarecer outra questão. Uma (e qualquer) língua é criada a partir da visão de mundo de cada sociedade que a compõe, sendo fruto de experiências pessoais, coletivas, e, portanto, culturais. 
Cada povo procura representar linguisticamente as divisões cronológicas de 'presente', 'passado' e 'futuro,' de modos diferentes. E por quê? Simplesmente porque os clãs não combinavam a maneira com que iriam confeccionar um idioma. Por exemplo, pensemos que, na Idade Antiga, uma certa comunidade ao norte da Europa não trocava e-mails ou se comunicava com tribos ao sul do mesmo continente via celular, MSN etc. Não havia gramática, nem sequer, escrita na maior parte dos casos. Então, obviamente, serviço de correio também não funcionava. Grosso modo, os povos primitivos contavam com mensageiros bilíngues. Enfim, a falta de contato verbal entre esses grupos sociais fez com que o tempo - enquanto fenômeno da natureza - fosse expresso de formas distintas, o que explica porque as estruturas verbais não são perfeitamente traduzíveis na transposição de uma língua para outra. A língua nasceu da necessidade de alguém se comunicar com o outro próximo a ele, e não com a finalidade de criar regras e padrões fabricados em laboratórios linguísticos.

Esta reflexão ajuda-nos entender que o tempo, enquanto fenômeno que se desdobra em dias, meses, anos, décadas, séculos e milênios, não corresponde necessariamente aos termos 'presente', 'passado' e 'futuro' que compõem o tempo verbal de uma determinada língua. Neste momento, o leitor deverá estar se perguntando: "O tempo que corre no relógio não é o tempo da gramática?” A resposta é 'Não!' O tempo da gramática (tense) é uma forma simbólica e imperfeita de representar o tempo 'tique-taque' (time). O primeiro tenta expressar o mundo ao redor, mas não consegue exprimir tudo que há neste universo de forma plena, o que cria um impasse entre time e tenses.

Então, imaginemos que, se existe um descompasso dentro de um mesmo idioma entre o fenômeno da natureza e aquilo que o representa, muito maior é o desajuste entre a comparação de tempos verbais entre uma língua e outra. Isto explica as diferenças de conjugação verbal entre o português e o japonês, o francês e polonês, o checo e o inglês, de forma que nem sempre encontramos tempos verbais perfeitamente traduzíveis entre dois códigos linguísticos. O Present Perfect, por exemplo, é vertido de diferentes formas para o português, e uma das conversões pode se dar de forma literal. Como direi adiante, esse tempo verbal não só possui usos distintos em língua inglesa, mas também oferece um leque de traduções inesperadas para o português.

Tais observações nos conduzem a dois pontos de análise: 1) que o Present Perfect seja plurissignificativo - possui muitos sentidos - em inglês, 2) e que os muitos sentidos em destaque nos levam a situações práticas bem diferenciadas em língua portuguesa. Ambas as afirmativas apontam para a seguinte conclusão: estudar a estrutura do Present Perfect à luz da Morfologia - voltada para a composição e classes de palavras - é algo insuficiente. É preciso, pelo menos, atingir o campo da semântica (estudo que observa as relações de significado entre as palavras) e o universo da pragmática (área do saber que discute as sutilezas e comentários indiretos do falante na prática da língua) para entendermos o que está em jogo.

Entretanto, antes de avançarmos para o Present Perfect dentro da Semântica e da Pragmática, voltemos às perguntas iniciais "será que o Present Perfect se refere ao 'agora' porque possui dentro de si o elemento present? E, se contém o nome present, por que não se reporta ao presente somente?" Sabendo agora que o rótulo present pode nem sempre 
equivaler ao 'presente do relógio', entendamos por que este tempo verbal possui tal nome. Ele se chama present, porque o primeiro de seus componentes (o verbo to have) é conjugado no Simple Present e não porque este tempo verbal esteja sempre falando do present time 'o presente tique-taque'. Isto explica porque have e has aparecem na conjugação do Present Perfect.

Conclusão, o fato de possuir a palavra present não significa dizer que o Present Perfect designe o presente em que nos encontramos. E por quê? Mais importante do que present é o termo perfect, que diz respeito à relação deste tempo verbal com o past time (aquilo que já aconteceu). Perfect é um vocábulo vindo de pefectum, designação de origem latina que forma tempos verbais voltados para o passado. Em língua portuguesa, encontramos uma terminologia que dialoga com tal palavra latina. Exemplo: 'pretérito perfeito, imperfeito, mais que perfeito', vem da raiz etimológica perfectum. Portanto, a ligação do Present Perfect com o passado do relógio é mais forte do que a do presente, principalmente se analisarmos certas situações, do ponto de vista do brasileiro, e não, de acordo com o gramático nativo de língua inglesa.

\section{O que é o Present Perfect, como entendê-lo e aplicá-lo?}

Como já adiantamos, o Present Perfect consiste em uma estrutura aplicada a diversos contextos em inglês e cujas traduções para o português são variáveis. Seria errôneo afirmar que não exista uma tradução do Present Perfect compatível com o português. De fato, existe uma possibilidade de equiparar, por exemplo, 'Tenho feito coisas legais' a 'I have done nice things'. $O$ ' $x$ ' da questão é que o transplante do Present Perfect para o Pretérito Perfeito Composto não pode se dar o tempo todo. É preciso entender inicialmente que tal estrutura da língua inglesa assemelha-se a um polvo cujos tentáculos nos remetem, individualmente, a um significado e tradução distintos. Dependendo do contexto, podemos traduzir I have done como 'faço', 'tenho feito' ou 'fiz', dependendo do contexto. Por isso, é preciso entender, inicialmente, que tal tempo verbal assemelha-se a um eixo cujos desdobramentos nos conduzem a casos diversos.

Inegavelmente, os gramáticos estrangeiros têm a preocupação de apresentar diferentes contextos para o Present Perfect, enfocando, assim, o aspecto plurissignificativo do mesmo. Contudo, como as gramáticas inglesas são vendidas para falantes de centenas de línguas no mundo todo, autores anglófonos não formulam materiais que vão de encontro às dificuldades específicas dos falantes do português. E é nesta brecha entre a cultura local e a global que o professor brasileiro precisa atuar com cuidado e perspicácia, na posição de facilitador da aprendizagem. Vejamos, por exemplo, que as definições clichê para o Present Perfect são: 1) a ação do passado que se estende ao presente, ou 2) a ação do passado cujos efeitos se percebem no presente.

Para ingleses, escoceses, irlandeses, galeses, australianos, canadenses ou estrangeiros habituados a pensar segundo a norma culta do inglês, a afirmativa número dois é plenamente compreensível, mas para a maioria dos brasileiros ou até mesmo norteamericanos (sem grande conhecimento de gramática), isto não faz sentido. As situações que se aplicam à segunda afirmativa acima são traduzidas para o português via Pretérito Perfeito - 'cantei, cantaste, cantou etc.' - o que, para o brasileiro, nada tem a ver com 
'efeitos que se percebem no presente'. Ora, você, leitor, deverá estar pensando: 'Se eu fiz alguma coisa e não estou mais fazendo, qual efeito isto exerce no tempo presente?' Dentro da ótica da língua portuguesa, a resposta é 'Nenhum!'

Para o brasileiro, o que importa é ação executada, e não até que ponto suas consequências abrangem o presente. Até aqui, nosso aluno leva a culpa de não pensar em inglês, o que não deixa de ser verdade. Porém a dificuldade de perceber resultados do passado no presente não é exclusividade dos falantes de língua portuguesa. Por uma questão de praticidade, os norte-americanos também pouco se importam com os efeitos do passado no presente e, várias vezes, trocam o Present Perfect pelo Simple Past, contrariado a gramática. Esta peculiaridade acaba afetando centenas de alunos brasileiros que assistem a filmes nos quais o inglês coloquial dos EUA é falado. Então, somando a experiência linguística do brasileiro aos exemplos antigramaticais dos norte-americanos, como entender o Present Perfect? Em face destes desajustes, gostaria de reapresentar as categorias que os gramáticos anglófonos apontam, associando o Present Perfect a ideias que, para o falante do português, se dividem em past time e past+present times. Contudo, antes de apresentarmos esta abordagem, gostaria de fazer o leitor refletir sobre o conceito de 'passado', relacionado ao tempo do relógio (time).

\section{Definindo, Particularizando e Contextualizando o Past Time}

Quando falamos de passado, muitas vezes não definimos com exatidão o que queremos dizer. Passado em que sentido? O passado como sua vida inteira? O passado como ontem? O passado como três anos atrás? O passado como instantes que quase se justapõem ao presente? O passado como memória, registro histórico? Enquanto algo que aconteceu há séculos, milênios atrás? À noção de ‘era uma vez’? Ou como momentos da vida que você não recorda bem? A partir desta reflexão, ponderemos o seguinte: "Será que, em inglês, usamos uma mesma estrutura para expressarmos todas as situações apresentadas?" A resposta é: "Não!" Olhe o esquema abaixo e considere a linha que atravessa os quadros como um passado contínuo, que se estende até o presente. Suponha também que cada quadrinho numerado seja um momento diferente da sua vida do qual você possa falar ou contar uma história quando quiser.

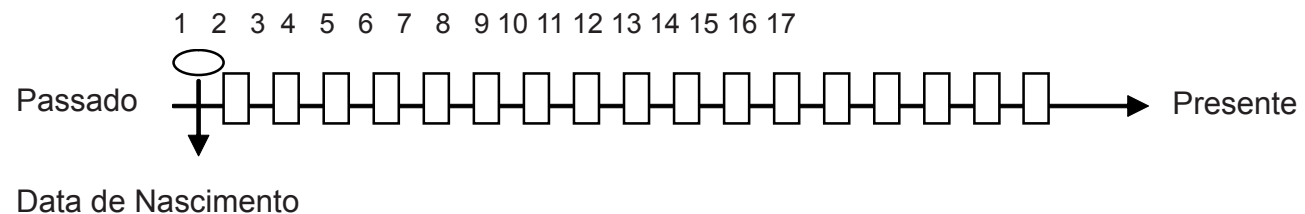

Data de Nascimento 
Em primeiro lugar, pergunte a si mesmo: é possível falarmos sobre todo nosso passado em breves comentários ou a biografia é a única forma de descrevermos nossa longa existência? Boa pergunta! Sim. Existe a questão do detalhamento ou concisão, o que interfere na maneira com que expressamos o passado em inglês. Ou seja, aqui começa a discussão entre Simple Past e Present Perfect: as duas estruturas que representam o past time com mais frequência em língua inglesa.

Para narrar um episódio que aconteceu ontem, por exemplo, você faz alusão a sua vida inteira ou se restringe a um determinado momento? É lógico que recorta o dia de ontem; dia este que pode ser representado por um quadrinho do esquema acima. Consideremos que tal quadrinho seja o 17. De outro modo, se você quiser se reportar a todo o seu passado, pensará na seta vertical da ilustração que, simbolizando a existência de alguém, inclui todos os quadrinhos ao mesmo tempo. Em outra situação, se disser que já foi a um lugar três vezes, você poderá selecionar os quadrinhos números 2, 11 e 16, por exemplo, englobando, em um só comentário, um passado remoto, representado pelo quadro 2 , um segundo passado não muito distante, simbolizado pelo número 11, e um terceiro bem recente, expresso pelo número 16. Então, daqui para frente, quando pensar em passado, delimite tal ideia com precisão, pois é a partir do recorte exato de time que conseguirá saber quando usar o Simple Past e o Present Perfect.

\section{O Emprego Contextual do Simple Past versus Present Perfect}

Voltando ao ponto inicial da linha de raciocínio quanto às diferentes configurações do past time, pense que, se quisesse contar uma história no passado, não poderia narrar o que aconteceu em diferentes quadrinhos ao mesmo tempo. Imagine que uma mesma pessoa conte, ao mesmo tempo, as histórias do quadrinhos número 3, 12 e 17. Isto seria uma loucura, e o leitor não entenderia nenhum dos três discursos. Como a língua exige linearidade - ou seja, que as palavras sejam ditas uma de cada vez-, é impossível discorrer sobre três acontecimentos simultaneamente. Então, se alguém relatar o que aconteceu ontem, por exemplo, deverá se ater ao quadrinho 17 somente. Assim o ouvinte saberá 'o que', 'quando' e 'onde' o fato se deu. Deste modo, o falante estabelecerá a noção de 'contexto' que distancia um momento passado de muitos outros.

No caso de uma narrativa, precisamos situar as informações sobre as quais falamos para que o interlocutor ou o leitor compreenda nosso discurso. Sendo assim, podemos concluir que uma história no passado necessita de precisão ou especificações que esclareçam o assunto tratado; caso contrário, tal situação ficará sem nexo. Para darmos coerência ao episódio contado, usamos expressões como last, ago, yesterday, porque elas indicam o momento exato em que algo ocorreu, sendo marcas temporais que definem se determinada história se refere ao quadrinho 3, ao 12 ou ao 17, por exemplo. Cada quadrinho contém uma história diferente dentro de si, e o tempo verbal que nos permite enxergar o passado picotado, observado em recortes separadamente, chama-se Simple Past. Ele é a estrutura responsável pelo desenvolvimento de um relato no passado e não se reporta a mais de um quadrinho ao mesmo tempo. Por quê?

Como já dissemos, uma história precisa de contexto, então o Simple Past trabalha com um quadrinho de cada vez, montando, por exemplo, a biografia de uma personalidade, se 
preciso for. Esclarecemos que, diferente de o que se ouve em cursos de inglês, o Simple Past não aparece em frases por causa de last, ago, yesterday. Ao contrário, o contexto que ele suscita é o que provoca a recorrência destas marcas temporais. E por que afirmamos isso? Seria muito estranho escrevermos um texto no qual cada linha contivesse last, ago ou yesterday. Entretanto, saiba que, se uma dessas expressões aparecer no início de cada história, a restrição temporal será feita e saberemos quando o fato ocorreu. Às vezes, a especificação de time vem através de datas ou outros indícios que nos norteiam cronologicamente, e não somente por meio das três palavras clichê supracitadas.

Enfim, mostramos até então que o passado do Simple Past implica em especificação temporal e contextual. Agora é necessário entender que, dentro de um quadrinho específico, é preciso ordem e lógica para desenrolar os detalhes da história. Afinal, sem a sucessão dos acontecimentos, nenhuma narrativa faz sentido; por isso o Simple Past exige a noção de sequência, representada por palavras como then, so, after that ou later, que dão à narrativa a sensação de começo, meio e fim.

Em oposição ao Simple Past, o Present Perfect não é um tempo verbal que desenvolve histórias. O mesmo até pode aparecer em uma narrativa do passado, mas não para compôla. Com o Present Perfect, fazemos comentários sobre algo ocorrido ao longo da vida sem muitos pormenores. Por exemplo, digamos que você já voou de asa delta em algum momento da sua vida. É óbvio que, dentro si, o leitor sabe quando isto aconteceu, que tal fato, por exemplo, seria representado pelo quadrinho 10 do organograma; mas, por motivos pessoais, não quer entrar em detalhes, preferindo omitir informações, ou fazer breve comentário, sem especificar o momento em que isso ocorreu. Neste caso, o leitor diria: I've flown a hang-glider. ('Já voei de asa-delta'). Diferente do Simple Past, o Present Perfect está mais preocupado com o fato do que com o contexto. Nesse caso, o contexto é mais aplicado a comentários breves, avulsos, arbitrários ou gerais.

Imagine também que alguém surja com a seguinte pergunta: Have you EVER been to Quinta da Boa Vista? ("Você já foi ALGUMA VEZ NA VIDA à Quinta da Boa Vista?"). Neste caso, a pessoa está ligando a linha do passado ao presente, formando um todo que percorre o momento em que você nasceu até agora. Em tal situação, o passado inteiro+presente que constituem sua existência é expresso pelo Present Perfect. Por quê? Porque, em tal pergunta, não estamos tratando de um recorte do passado, de um quadradinho em particular, mas aludindo à linha que se estende até o presente. Falamos de um passado global, que não pode ser expresso pelo Simple Past, mas pelo Present Perfect.

Esta reflexão nos conduz ao uso do always e never junto à última estrutura verbal, como se lê no seguinte exemplo: Dan has always/never been a good boy - ('Dan sempre/nunca foi um bom menino. Neste caso, always (ou never) não se refere(m) à rotina, ou à frequência com que uma certa ação é feita no presente, tal como em I always/never go to school (Nunca vou à escola) - mas abrange a atual existência do sujeito, o que justifica a ideia de passado+presenste. No caso de pessoas falecidas, usamos o Simple Past, dizendo, por exemplo, Dan was always/never a good boy - também traduzido para o português como 'Dan sempre/nunca foi um bom menino'. O uso do Simple Past, neste caso, justifica-se pela evidência de que mortos não atuam no presente. Vale ressaltar que tal diferença não 
aparece em português, mas precisa ser observada pelo brasileiro usuário de língua inglesa. Dentro desta situação, é possível dizermos que o Present Perfect marca a continuidade da ação até presente e que o Simple Past não se estende ao 'agora'.

Na junção passado e presente, encontramos também os usos de yet e still. Traduzidos como 'ainda', ambos têm por finalidade indicar que a ação não ocorreu nem no passado nem no presente. Exemplo: I still haven't read that novel, ou I haven't read that novel yet. Frases estas que vertemos para o português como 'Ainda não li aquele romance'.

Então, até aqui aprendemos que o Present Perfect pode ser usado para: a) mencionar uma ação passada de forma vaga, rápida, sem referência temporal precisa, em oposição ao passado narrativo do Simple Past; b) ao somatório de todo o passado+presente, o que não esgota o uso do Present Perfect. Este tempo verbal também é usado para somar uma parte do passado ao presente, como veremos a seguir.

Voltando a usar o organograma como ilustração, imagine que o quadrinho 12 equivalha ao momento em que você se tornou adulto e que, desde então, o leitor vem trabalhando em uma certa empresa. Neste caso, entenderíamos passado como um traço sobre a linha da existência, ligando o quadrinho 12 ao presente. Para expressar esta ideia em português, você diz: "Trabalho/Estou trabalhando/Tenho trabalhado nesta empresa há nove anos". Obviamente, o verbo ‘trabalho' ou 'estou trabalhando' aqui não se referem ao agora, mas ao transcurso de um determinado ponto do passado até este momento, bem expresso por 'tenho trabalhado'. Em casos como este, dizemos em inglês I have worked at this company for nine years, e não I work ou I'm working... Em tais situações, associamos o Present Perfect a since e for. Portanto, para designar "Nós nos conhecemos desde 2001", dizemos, em inglês, We've known each other since 2001. O uso do for precisa ser retratado com cuidado, porque pode ser utilizado junto ao Present Perfect e ao Simple Past em casos diferentes. Se alguém diz You have studied English (for) almost seven years, significa que os estudos estão em andamento. No caso de You studied English (for) seven years, você já finalizou o curso de língua estrangeira. Em ambos os casos, o emprego do for é opcional, por isso aparece entre parênteses.

Recapitulando, até aqui aprendemos que: a) O Present Perfect não é inerentemente narrativo; b) ele pode fazer menção a um quadrinho, ou mais de um ao mesmo tempo através de comentários vagos, sendo traduzido pelo Pretérito Perfeito Simples - cantei, cantaste, cantou; c) o Present Perfect soma todo o passado ao presente, também traduzido pelo Pretérito Perfeito; d) o Present Perfect funde parte do passado ao presente, sendo transposto para o português pelo Presente do Indicativo Simples - canto, cantas, canta etc.; pelo Presente do Indicativo Composto - estou/estás/está cantando etc., ou pelo Pretérito Perfeito Composto - tenho/tens/tem cantado etc.. Aliás, esta terceira possibilidade é a única manifestação de tradução literal entre o português e inglês no que tangue ao Present Perfect.

Pensando no passado com outro formato, consideremos mais uma aplicação da estrutura verbal em voga. Imagine que você já tenha ido à Quinta da Boa Vista três vezes (ao longo da vida), e suponhamos que tais visitas correspondam aos quadrinhos de número 6, 11 e 17, que representam, respectivamente, um momento da infância, um da adolescência, outro da juventude. Se você respondesse "Já fui três vezes", você não usaria o Simple 
Past, e sim o Present Perfect. Por quê? Porque, com o Simple Past, você teria que contar um relato de cada vez. Visto que não é possível contarmos três histórias ao mesmo tempo, dizemos: I have been there three times, mencionando, por alto, três fatos do passado sem precisão temporal. Por meio de tal frase, o ouvinte não tem como descobrir quando aconteceu a primeira, a segunda ou a terceira vez em que fomos à Quinta da Boa Vista.

Diferindo-se do Simple Past, o Present Perfect é capaz de agrupar três ou mais experiências distintas em um só comentário, sem contar nenhuma das três histórias. Assim, o usuário da língua somente as cita simultaneamente, mas não as narra. Outro diferencial é que usamos I've been to para nos referirmos a lugares que visitamos e dos quais retornamos em vez de I've gone to. Esta segunda expressão quer dizer que alguém foi a certo lugar e não voltou. Como todos nós, felizmente, retornamos sãos e salvos da Quinta da Boa Vista, usamos a primeira expressão supracitada.

Reiterando o que já foi dito, podemos afirmar que o Present Perfect pode: 1) ser usado em comentários gerais, quando não temos a intenção de prolongar a conversa. 2) compreender vários quadrinhos ao mesmo tempo; 2) conectar todo (ou parte do) passado ao presente.

Além disso, o Present Perfect pode ser usado, quando fazemos uma pergunta sem termos sequer certeza de que a pessoa praticou a ação ou não. Veja este exemplo: By the way, have you taken the medicine? (Por acaso, você tomou o remédio?) - Esta pessoa fez uma pergunta vaga, sem saber, ao menos, se o remédio foi ingerido ou não. Já se o pai, por exemplo, tivesse ordenado ao filho tomar o remédio, e voltasse mais tarde, a fim de checar se o ultimato foi obedecido, ele perguntaria: Did you take the medicine? (Você tomou o remédio?). Note que a escolha do Simple Past ou a do Present Perfect está respectivamente relacionada, neste caso: 1) à certeza e à incerteza; 2) à polidez e à repressão.

Grosso modo, Simple Past está atrelado à retomada de um informe prévio, já o Present Perfect, pode ser associado ao desconhecimento do assunto. Em casos de perguntas em que não são necessariamente interrogações, mas manifestações emotivas como: 'Nossa, você emagreceu? Podemos tanto dizer 'Wow, you have lost weight?' ou 'You lost weight?' porque, se por um lado o falante não tinha tomado ciência do emagrecimento, agora passou a tomar. Por isso, o Simple Past e o Present Perfect são possíveis neste caso e a forma afirmativa do verbo é aceitável porque não se trata de uma pergunta literal, mas retórica. Então, até aqui aprendemos que o Present Perfect está ligado: a) a comentários vagos no passado sem necessidade de contextualização, b) à existência de alguém ainda em vida; c) a um recorte do passado junto ao presente; d) a coleta de diferentes momentos do passado em uma mesma frase; d) a perguntas envolvendo dúvida ou ditas de forma educada; e) a manifestações de surpresa.

Se o Simple Past, como já dissemos, difere-se do Present Perfect, porque o primeiro exige contexto, o segundo se aplica a circunstâncias que denotam 'imprecisão temporal'. Anteriormente, traduzimos ever como 'já', referindo-nos 'a um momento da vida, provavelmente distante do agora'. Entretanto, se alguém disser: 'Professor, já terminei o exercício'; o aluno não está se referindo a um momento remoto da existência, mas há minutos atrás, não divulgados intencionalmente. Talvez ele tenha terminado a tarefa escolar há um, dois, três, quatro, cinco minutos, mas não julgou importante relatar este detalhe. Digamos que o mesmo aluno esteja mais preocupado com a ação do que com 
o tempo, por isso, utilizou uma expressão temporal vaga como o advérbio already, traduzido como 'já' em casos afirmativo e interrogativo. Already também se justapõe a yet, significando 'já' em perguntas e 'ainda' em casos de negação. Embora yet seja preferido pelos gramáticos em forma interrogativa, é possível encontrarmos already em perguntas, sobretudo em contextos informais. Vejamos os seguintes exemplos:

1. They have already arrived home. 'Eles (-as) já chegaram a casa'

2. Have you got(ten) dressed yet? 'Já se vestiu?'

3. Have you already got(ten) dressed? (inglês oral) 'Já se vestiu?'

4. We haven't come to a conclusion yet. 'Ainda não chegamos a uma conclusão'.

É justamente aqui que recai o maior descompasso entre o falante nativo do português e aquele que tem inglês como língua materna. Para os brasileiros, importa que a ação tenha sido concluída, enquanto, para os gramáticos anglófonos, que não haja mais tarefas a serem feitas neste momento. Daí, a explicação de que o Present Perfect diz respeito a uma ação passada, cujos efeitos recaem sobre o Present Perfect. Considerando este desajuste cultural entre o português e o inglês, talvez seja mais fácil conceber que, em frases com already e yet, a ação tenha sido concluída e que o Pretérito Perfeito deva ser traduzido por meio do Present Perfect. Deste modo, a compatibilidade entre as línguas parece ficar mais visível e compreensível. É importante acrescentar que, em função de already e yet serem expressões sem especificação temporal, a frase não sofre grandes perdas, quando omitidas. De fato, as três frases anteriores podem transmitir (praticamente) a mesma ideia, se fossem ditas assim: They have arrived home ou Have you got(ten) dressed? etc.

Em se tratando de ações próximas ao presente, ainda existe o uso do Present Perfect com just. Em tal situação, o tempo verbal em discussão é traduzido pela expressão 'acabei, 'acabaste', acabou etc. de fazer'. Exemplo: She has just taken a shower. - 'Ela acabou de tomar banho'. I've just got(en) home. - 'Acabei de chegar a casa'. Contudo, gramáticos norte-americanos, particularmente, aceitam o uso do Simple Past junto do just, mantendo o mesmo sentido do Present Perfect. Assim, é possível dizer She just took a shower e I just got home nos EUA e no Canadá. Portanto, até aqui, aprendemos que o Present Perfect: a) refere-se a comentários avulsos no passado, contendo expressões temporalmente imprecisas, ou sem locução adverbial de tempo alguma; b) não é um tempo narrativo; c) permite-nos expressar ideias ligadas a todo o passado+presente ou parte do passado+presente; d) agrupa mais de uma experiência do passado em um único comentário; e) cabe em perguntas ocasionais, proferidas educadamente; f) reações emotivas g) ações que acabaram de acontecer.

O último caso de Present Perfect que apresentaremos trata-se de have/has got, uma expressão idiomática que equivale ao verbo to have com o sentido de 'possuir'. Enquanto é mais comum ouvirmos alguém dizer I have a car nos EUA ou no Canadá, na Inglaterra e em outras ex-colônias britânicas, ouvimos frequentemente I've got a car, significando a mesma coisa. Tal expressão, diferente dos outros casos de Present Perfect, pois se reporta somente ao present time; de sorte que a frase I've got something to tell you, sinônima de 
I have something to tell you, equivale a 'Tenho algo para lhe contar'. Apesar de 'have got' ser menos empregado nos EUA, esta locução verbal deu origem ao uso coloquial de got enquanto sinônimo de have. Exemplo: I got something to tell you é um modo informal de dizer I have something to tell you. A substituição de have to, no sentido de 'ter que', ocasionou a existência de got to, que, é transformado em gotta na linguagem oral informal, estadunidense, ou canadense. Então, se quisermos tecer o seguinte comentário: 'Temos que ir ao banco', podemos usar todas as possibilidades a seguir: I have to go to the bank; I've got to go to the bank; I got to go to the bank; I gotta go to the bank. Lembre-se somente que o penúltimo uso é informal, e que o último não se enquadra na linguagem Enfim, o Present Perfect pode ser apresentado para o brasileiro na disposição encontrada abaixo, incluindo as seguintes categorias semânticas:

\section{Past Time:}

a) Emphasis on the Past Action (Ênfase na ação passada);

b) Random Comment on the Past (Comentário Avulso sobre o Passado);

c) Random Questions (Perguntas sem presciência);

d) Random Past Expericences (Experiências Diversas no Passado);

e) Recent Past-(Passado Recente).

\section{Past+Present Time:}

a) Lifetime Experience (O Tempo de Existência do Sujeito)

b) A Remaining Past Experience (Uma Experiência Passada que se estende ao Presente)

c) Inaccomplished Present Action (Ação Não Executada);

\section{Present Time:}

a) Have-Got Present (Presente com Have Got)

\section{Quando usar o Present Perfect e o Simple Past em conversas?}

Antes de apresentar um exemplo prático para o uso de ambos os tempos verbais, veja a tabela que se segue, para recordar as diferenças contrastivas entre os dois tempos verbais em questão:

Agora, leia o diálogo abaixo, observando os comentários gramaticais:

A: Have you ever been to Parati? (Você já foi a Parati?)

(Pergunta casual - Present Perfect)

B: Yes, I have. (Sim, já).

(Resposta vaga - Present Perfect) 
O Present Perfect para Brasileiros: Tradução Transcultural no Ensino-Aprendizagem de Língua Inglesa

Heleno Álvares Bezerra Júnior

Artigo de Demanda Contínua

\begin{tabular}{|l|l|}
\hline \multicolumn{1}{|c|}{ SIMPLE PAST } & \multicolumn{1}{c|}{ PRESENT PERFECT } \\
\hline Para narrar histórias com começo meio e fim. & $\begin{array}{l}\text { Para fazer comentários com expressões temporais } \\
\text { imprecisas ou para encurtarmos assuntos. }\end{array}$ \\
\hline $\begin{array}{l}\text { Para fazermos perguntas sobre fatos de nosso } \\
\text { conhecimento ou para pressionarmos alguém. }\end{array}$ & Para perguntarmos sobre coisas de forma casual. \\
\hline Para nos referirmos a um momento da vida & $\begin{array}{l}\text { Para nos referirmos a vários momentos da vida } \\
\text { como um todo. }\end{array}$ \\
\hline Para enfatizar o tempo passado. & Para destacar a ação passada. \\
\hline
\end{tabular}

A: Oh, really? How many times have you been there? (Ah, é? Quantas vezes esteve lá?) (Pergunta sobre vários fatos passados simultaneamente - Present Perfect)

B: I've been there three times. (Eu estive lá três vezes.)

(Resposta para mais de um fato passado, citado ao mesmo tempo - Present Perfect)

A: Really? When did you last go there? (É mesmo? Qual foi a última vez que você foi lá?)

(Pergunta sobre um fato específico com marca de tempo restrita, neste caso, last.)

B: I spent my last vacation there.(Passei minhas últimas férias lá)

(Resposta específica sobre um único quadrinho do passado.)

A: What good things did you do there? (O que você fez de bom lá?)

(Pergunta específica quanto ao quadrinho já mencionado, o que provoca uma situação narrativa.)

B: Well, I did many things. Right there, I always went to the beach, swam in the sea... and... sunbathed, er...went sightseeing on a boat. You know, I met a very pretty girl who went out with me then. Anyway, it was great! - (Bem, fiz muitas coisas. Lá, eu ia à praia sempre, nadei no mar... e... tomei banho de sol, é... fiz um passeio de barco. Essas coisas. Conheci uma garota bonita que saiu comigo na ocasião. Enfim, foi ótimo!)

(O falante usa o Simple Past para narrar um fato do passado com uma sequência de circunstâncias).

No exemplo acima, always aparece em um contexto diferente dos outros dois já mencionados. Durante a explanação do item 2.2.2, usamos o mesmo advérbio junto ao Present Perfect para falar de experiências de pessoas vivas, e junto ao Simple Past para falar daqueles que se foram. No entanto, always aparece com um terceiro sentido neste último exemplo. E por quê? Lembremos que always seguido do Present Perfect engloba mais de um quadrinho. Quando B diz I always went to the beach, não está se referindo à vida toda ou à rotina no presente. Ao contrário, fala do que aconteceu dentro do quadrinho que representa as últimas férias sobre as quais narra. $\mathrm{O}$ mesmo seria se, nos 
limites da mesma situação, B afirmasse: During my vacations, I went to the beach many times (Durante as férias, fui à praia muitas vezes). Ou seja, durante uma breve temporada específica, eu sempre fui à praia. Em tal situação, não falamos de coisas que se sucedem ao longo da vida, mas dentro de um contexto delimitado. Então, quando always ou many times aparecerem com o Simple Past, vão estar contidas em situações específicas, em vez de espalhadas na linha do tempo.

\section{E o Present Perfect Continous ou Progressive?}

Para simplificar a diferença entre o Present Perfect e o Present Perfect Continuous, digamos, em princípio, que o segundo tempo verbal seja uma forma enfática do primeiro. Por exemplo. Eu posso dizer que 'Trabalho (ou tenho trabalhado) em uma empresa há anos' - I've worked at a company for years, assim como é cabível afirmar 'Venho trabalhando em uma empresa há anos' - I've been working at a company for years. Grosso modo, esta é a distinção entre os tempos verbais, ou seja, o Present Perfect Contínuous intensifica o efeito progressivo da ação. Entretanto, existem restrições para o emprego da combinação entre os aspectos Perfective e o Progressive (que particularmente compõe os tempos Continuous, também conhecidos como Progressive). Em língua inglesa, verbos que designam atividades mentais como, por exemplo, 'pensar' (think), 'conhecer', 'sugerir' (suggest) etc. não admitem o Continuous ou Progressive por serem considerados estáticos. Para melhor conhecimento do assunto, consulte gramáticas que apontem a diferença entre stative verbs e dynamic verbs, pois somente estes admitem as formas Continuous. Contudo, para assinalar uma breve distinção entre as categorias, imaginemos que o verbo run (correr) - que indica movimento físico - aceita a conjugação Progressive, enquanto consult (consultar) - verbo que designa uma ação mental - não é compatível com o Continuous. Portanto, o verbo run permite-nos compor frases tais quais He's been running from the police (Ele tem fugido/vem fugindo da polícia) no Present Perfect Continous ou Progressive; por outro lado, para dizer, 'Ela tem consultado fontes bibliográficas confiáveis', falamos: She has consulted reliable bibliographic references e não usamos o Present Perfect Continous, já que consult é um verbo estático. Em suma, somente os verbos dinâmicos como run aceitam a ênfase que Perfect Continous/ Progressive transmite. 


\section{Considerações Finais}

O Present Perfect é tempo verbal que apresenta traduzibilidade múltipla em língua portuguesa, tornando-se objeto de estudo de teóricos da tradução transcultural. Como sugerimos inicialmente, o Present Perfect pode ser comparado a um polvo, cujos tentáculos apontam para aspectos diversos da língua, viabilizando, por conseguinte, diferentes formas de tradução para o português. Ressaltamos que a melhor forma de entender tal estrutura verbal é pensar em inglês. No entanto, para os que ainda não conseguiram tal façanha, ou para tantos outros fluentes que aplicam o Present Perfect corretamente de forma intuitiva, esperamos que o presente artigo tenha sido esclarecedor, proporcionado respostas eficazes. A intenção é desmitificar o verbo em língua inglesa; sobretudo, para alunos universitários que, às vezes, já atuam em cursos de inglês. Ressaltamos que, por mais que o leitor pense: 'Não preciso explicar tanto, quando lecionar em escolas ou cursos de inglês'. Mesmo assim, deverá saber quando utilizar o Present Perfect, corrigir redações com segurança, prestar concursos, exames de proficiência, participar de entrevistas e congressos em língua estrangeira, publicar ensaios em língua inglesa, e muito mais. Portanto, veja o Present Perfect não como um obstáculo, mas como um dos mecanismos que compõem o idioma com o qual lidamos com tanto prazer. 


\section{Notas}

1 Cuja tradução compomos do seguinte modo: "Um dos propósitos fundamentais da aprendizagem através da reflexão é o aprimoramento qualitativo do ensino-aprendizagem. Compreender o papel de valores pessoais e profissionais neste processo é importante. Valores dão a educadores a noção de identidade profissional, motivam e promovem razões para o aprendizado".

2 A tradução do trecho pode ser expressa da seguinte forma: "em nível de tradução entre idiomas, não existe plena equivalência trivial entre unidades-código".

\section{Referências}

ABBS, Brian \& FREEBAIRN, Ingrid. Blueprint one. Madrid: Longman, 1990.

ALEXANDER, L. G. Longman English grammar. London: Longman Publishing Group, 1988.

BARBOSA, Heloísa Gonçalves. Procedimentos técnicos da tradução: uma proposta. Campinas: Pontes, 2004.

BATALHA, Maria Cristina \& PONTES, Geraldo Ramos. A tradução como prática da alteridade. Cadernos de Tradução, Florianópolis, n. XIII: 27-44, mar/jul. 2004.

BEAUMONT, Digby. Heinemann English grammar: intermediate. New York: Heinemann, 1992.

CATFORD, John Cunnison. A linguistic theory of translation. London: Longman, 1965.

CELCI, MURCIA M. \& FREEMAN, LARSEN D. “The tense-aspect system: forms and meanings" In: The grammar book. Boston: Heinle \& Heinle, 1993. p. 61-79

CHALKER, Sylvia. Current English grammar. New York: Macmillan Edition, 1984.

COE, Norman. Grammar spectrum 3: English rules and practice: intermediate. Oxford: Oxford, 1995.

CRYSTAL, David. Some current trends in translation theory. The Bible Reader. London, vol. 27 no. 3: 322-9, July 1976.

DOWNING, Angela \& LOCK, Phillip. A university course in English grammar. New York: Prentice Hall, 1992.

FIRTH, John Rupert. The tongues of men. London: Watt \& Co., 1937.

GENTZLER, Edwin. Trad. Marcos Malvezzi. Teorias contemporâneas da tradução. São Paulo: Madras, 2009.

GHAYE, Tony. 'Preface'. In: ---. Teaching and learning through reflexive practice: a practical guide por positive action. London: Routledge, 2011. p. 10-11

GREENBAUM, Sidney \& QUIRK, Randolph. A student's grammar of the English language. London: Addison Wesley Publishing, 1991.

JACOBSON, Roman. On linguistic aspects of translation. In: VENUTTI, Lawrence. The translation studies reader. London \& New York: Routledge, 2000. p. 113-8

LEECH, Geoffrey. Meaning and the English verb. London: Pearlson ESL, 2004. 
LEECH, Geoffrey and SVARTVIK, Jan. A communicative grammar of English. London: Pearlson ESL, 2003.

MURPHY, English grammar in use: intermediate. Cambridge: Cambridge, 1985.

NIDA, A. Eugene. The theory and the practice of translation. Boston: Brill, 1965.

QUIRK, Randolph et al. A comprehensive grammar of English language. London: Addison Wesley Publishing, 1985.

QUIRK, Randolph et al. A university grammar of English. Essex: Longman, 1973.

RICE, Chris. Hamlet by William Shakespeare: adaptation for pre-intermediate students. London: Penguin, 2000.

RICCEUER, Paul. Sobre a tradução. Trad. Patrícia Lavelle. Belo Horizonte: UFMG, 2011.

SOARS, John \& SOARS, Liz. American headway 2. New York: Oxford, 2001.

SWAN, M. \& WALTER, C. How English works. New York: Oxford, 1997.

WOODS, Edward and McLEOD. "Verb Tenses and Aspects". In: Use of grammar: meaning and form. London: Prentice Hall College Division, 1990. 